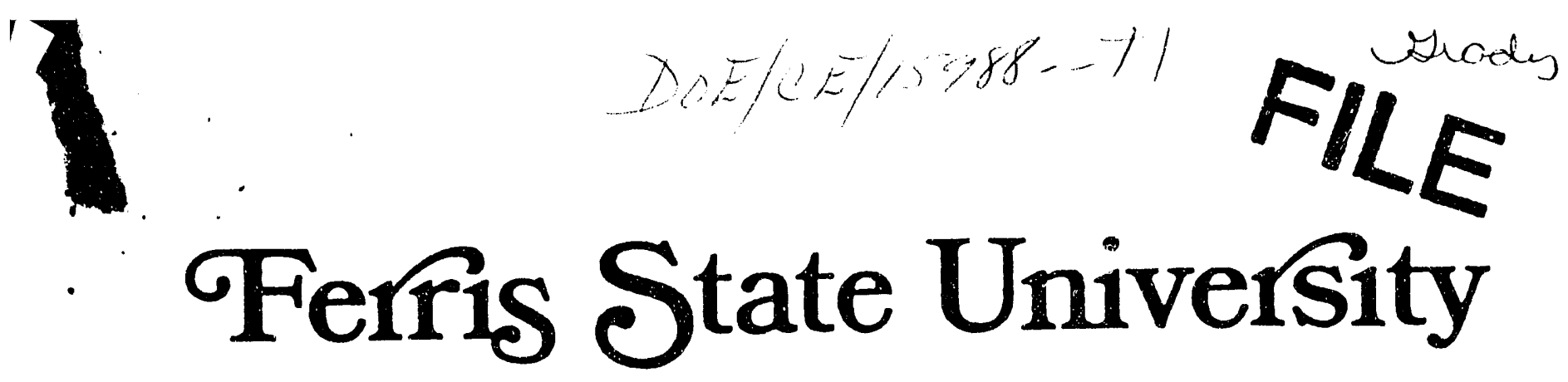

DOE/CE/15988--TI

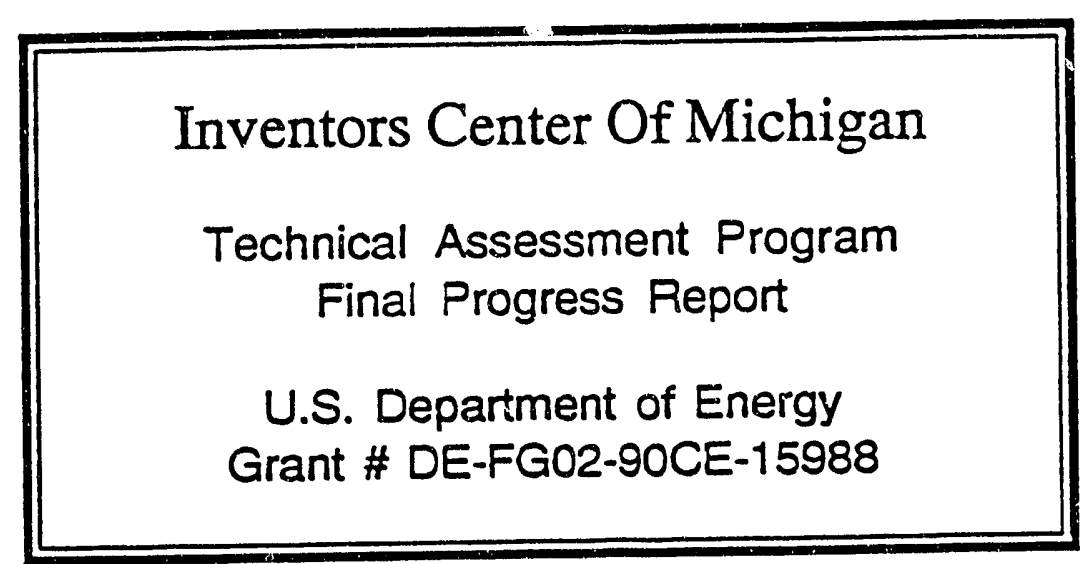

DE93 006067

\title{
DISCLAIMER
}

This report was prepared as an account of work sponsored by an agency of the United States Government. Neither the United States Government nor any agency thereof, nor any of their employees, makes any warranty, express or implied, or assumes any legal liability or responsibility for the accuracy, completeness, or usefulness of any information, apparatus, product, or process disclosed, or represents that its use would not infringe privately owned rights. Reference herein to any specific commercial product, process, or service by trade name, trademark. manufacturer, or otherwise does not necessarily constitute or imply its endorsement, recommendation, or favoring by the United States Government or any agency thereof. The views and opinions of authors expressed herein do not necessarily state or reflect those of the United States Government or any agency thereof.

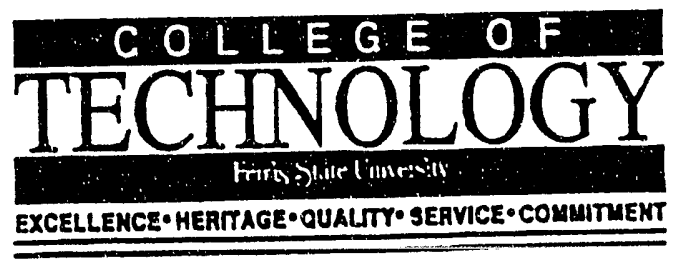

Technology Transfer Center 1020 E. Maple St.

Big Rapids, MI 49307

(616) $592-3774$

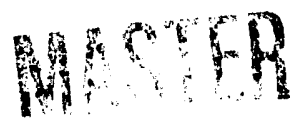

\footnotetext{
EXCELLENCE•HERTAGE・QUALTY SEAVICE• COMUITUENT
}

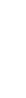




\section{Inventors Center of Michigan \\ Technical Assessment Program \\ Final Progress Report}

\section{Overview}

The Technical Assessment Program at the Inventors Center of Michigan is designed to provide independent inventors with a reliable assessment of the technical merits of their proposed inventions. Using faculty from within Ferris State University's College of Technology an assessment process examines the inventor's assumptions, documentation, and prototypes, as well as, reviewing patent search results and technical literature to provide the inventor with a written report on the technical aspects of the proposed invention.

\section{Project Description}

The Technical Assessment will address the technical merits of an invention from an engineering perspective, providing the inventor with a deeper level of analysis on the proposed invention than may have already been completed. The Technical Assessment is appropriate in the early stages of the product development process to help eliminate investment of resources into unpromising ideas, while identifying and channeling resources towards more promising inventions. The Technical Assessment focuses on the following factors.

$$
\begin{aligned}
& \text { * Development Status } \\
& \text { * Documentation \& Validity of Assumptions } \\
& \text { * Literature \& Technology Review } \\
& \text { * Preliminary Patent Search } \\
& \text { * Production Feasibility } \\
& \text { *Technical Analysis }
\end{aligned}
$$

The inventor client receives a Technical Assessment Report which summarizes the strengths and weaknesses identified in all of the above evaluation factor areas.

is

The Technical Assessment is completed using faculty and staff from the Ferris State University's College of Technology. The Technology Transfer Center is the economic development outreach program of the College which has over 170 engineering and technical faculty in a wide range of disciplines with recognized 
expertise in the areas of product design, plastics technology, energy management systems, automotive and heavy equipment technology, and manufacturing engineering technology. The Technology Transfer Center and the Inventors Center provide inventors with access to these resources through the Technical Assessment Program.

The Technical Assessment service is an extremely useful service particularly for the novice inventor who quite often is unfamiliar with: the state of the art in the field of the proposed invention, the size and expense of the development process, the validity of the assumptions used, and reliable estimates of the thermodynamic or mechanical efficiencies of the proposed invention. The Technical Assessment is not intended to provide in depth research into all the factors identified, rather it is designed to provide the inventor with an early stage assessment of the technical merits and feasibility of a proposed invention.

\section{Program Performance}

During this initial start-up year of the Technical Assessment program significant progress was made to develop the new service offering. The major events and milestones are summarized in this report.

To offer the Technical Assessment service to inventors throughout the country one of the first needs was to develop a set of materials that can be used for the submission of inventions for evaluation in a common format. A Technical Assessment questionnaire was developed for this purpose which will be completed by the inventor and retumed to the Center with a Ferris State University Non-Disclosure Agreement. Copies of these two documents are attached as Appendix A. The questions address the following areas: idea description, stage of development, mechanical environment, market environment, legal environment, and development plan. The inventor is provided the opportunity to ask specific questions to be answered during the assessment process.

A fact sheet on the Technical Assessment program has been written and printed for marketing purposes. This sheet describes the benefits of obtaining an independent review, the assessment process, and the procedures for submitting an idea for evaluation. A copy of this publication is attached to this report along with all the printed materials used in the program.

\section{Client Projects}

Technical Assessments were completed on 13 inventor products that were submitted to the Inventors Center. Approximately 60 inventors expressed an interest in obtaining a Technical Assessment however many did not return product information after receiving the materials in the mail, some indicated that the cost of $\$ 500$ was more than they were willing to invest into their product idea. A summary of the Technical Assessments completed is presented below with a brief title of invention, description of project, and college department of faculty completing project. 
Invention

Diesel Heat Exchanger

Fiber Optic Display

Refrigeration Compressor

Fisherman's Scissors

Humidifier

Door Opener

Insertion Tool

Hydraulic Tool

Fencing Hardware

Plastic Extrusion

Computer Workstation

Vacuum Cleaner

Carrying Case
Project Description

Technical Assessment

Technical Feasibility

Technical Assessment

Design review \& Proto.

Tech. Review \& Design

Tech. Review \& Design

Technical Feasibility

Technical Assessment

Tech. Review \& Proto.

Manufacturability

Design Review

Competitive Prod.

Evaluation

Manufacturability
Faculty Dept.

Energy Mgmt.

Optometry \&

Design Consit.

Energy Mgmt.

Tool Design

Plastic Eng.

FEA Consit.

Plastics Eng.

Plastics Eng.

Prod. Design \& FEA Consit.

Plastics Eng.

Prod. Design

Design Team

Plastics Eng.

\section{Project Results}

The Department of Energy funding for the Technical Assessment project was critical for initiating this new service to inventors which will be continued. The program allowed inventors access to technical assistance while the overhead costs of developing such a service were not borne by the inventors.

Two of the inventor products have already made it to the market, with several other continuing in development. Roughly half of the evaluations indicated that further investment into development should be limited and cautious. 


\title{
INVENTORS CENTER OF MICHIGAN
}

Manufacturing Resource and Productivity Center

Ferris State University

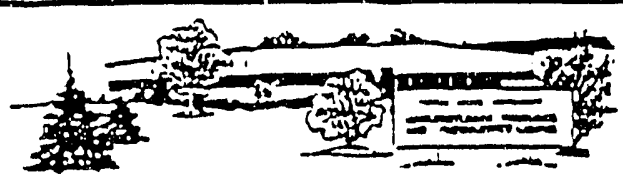

\section{TECHNICAL ASSESSMENT}

\begin{abstract}
A Technical Assessment provides inventors or small companies with an opportunity to receive an independent third party review of the technical merits and feasibility of their inventions earty in the development process.
\end{abstract}

Benefit to the Inventor: A Technical Assessment provides the inventor with access to technical and engineering personnel with appropriate expertise for the field of invention. Taese technical reviewers will issue an opinion on the proposed invention following an assessment of the following factors.

- Assessment of the validity of the assumptions used and claims made by the inventor.

*:Examination of existing documentation for accuracy and completeness.

- Preparation ot rough technical calculations of the mechanical or thermodynamic efficiencies of the invention (as required).

* Examination of production feasibility of the invention and an early estimation of the manufacturing: cost.

- Completion of a preliminary patent search and comparison to the state of the art in the field of invention.

* Develop recommendations for further research or testing.

The Technical Assessment is not designed to provide in-depth researci into all of the factors identified. rather ir is designed to provide the inventor with an early siage assessment of the tecianical feasiouiity or a proposed invention. A Tecinical Assessment aids the inventor and potential investors in maising the decision to proceed with the development of the proposed invention or not. In this manner. resources can be channeied towards the more promising inventions. and unpromising ideas can be abandoned eariy in the deveiopment process. therejy conserving capital resources. 
Procedure: Forms to request a Technical Assessment can be obtained by writing or calling the Inventors Center of Michigan. After the completed forms are returned to the Inventors Center the inventor may be called to provide additional details, clarification, or to send a prototype. The assessment process will take 8 to 12 weeks to complete.

Once the completed forms are received by the Inventors Center, staff will conduct a literature and technology search and a preliminary patent search. At that point a faculty member from within Ferris State University's College of Technology with an appropriate technical background will be assigned to provide comment on the technical factors previously identified. There are over 170 technical and engineering faculty in the College of Technology representing a broad and diverse base of expertise. A final report will be prepared which identifies the technical strengths and weaknesses of the proposed invention, suggests recommendations for further development, and contains an opinion on the appropriateness of continued development.

Protection: A non-disclosure form will be sent to the inventor along with the Request for a Technical Assessment. This form should be completed and returned with the completed assessment forms. All staff and faculty who will work on the Technical Assessment will be required to sign this agreement before any confidential materials are disclosed. At the Inventors Center at Ferris State University all confidential materials remain in locked flles and appropriate precautions are taken to ensure confidentiality.

Cost: The standard cost for a Technical Assessment is $\$ 500.00$, and a check should be made out to "Ferris State University / MRPC" when submitring an idea for evaluation. In specific circumstances, the cost of a Technical Assessment may exceed the standard cost due to an unusual amount of research that may be required. In that circumstance the inventor will be notified prior to the start of any work of the extent of additional charges. Once the Technical Assessment process has started, the fee cannot be refunded, but every effort will be made to satisfy the clients need. 


\section{NON-DISCLOSURE AGREEMENT}

The non-dlsclosure agreement for a new product is submitted to the Ferris State University (University) Manufacturing Resource add Productlvity Center (MRPC) Imventors Center of Michigan for manufacturing consideration. In signing this non-dlsclosure agreement I understand that:

1. The employees, agents, consultants, or representattves ("evaluators") of the Manufacturing Resource and Productivity Center ("MRPC") of Ferris State University, whose signature is shown below agrees with the undersigned imventor(s) ("irventor") as follows conceming evaluations of certain ideas, concepts, trade secrets, know-how (the "disclosures") which may be disclosed by the Inventor to the MRPC.

2. The written materials, documents, or other tangible expression of any disclosures provided by the Inventor shail be consficuously marked "CONFIDENTIAL Each verbal conversation or transmission of any disclo sure shal' ie stated as such. Items and material not so marked or identifled by the Inventor shall not be covered by this agreement.

3. The MRPC shail treat disclosures as confidential and will not disclose them to any other person except its evaluators as may be necessary to perform MRPC evaluation. Prior to performing evaluations on the disclosures, evaluators shall sign the ayreement.

4. The MRPC shall not exploit in any fashion, whether by manufacture, sale, license, or use, any of the disclosures, evaluators shall sign the agreement.

5. The disclosures are the proprietary property of the Inventor uniess they are: a)at present within the public domain or which at somelater time enter the public domain by another partyother than the MRPC or its evaluators; b)already known to MRPC or of record in the files of MRPC at the present time; or c) disclosed to the MRPC by a third party as a matter of rights.

6. Without limitation, an item shall be considered the public domain if it is published or publicly available, or if it is known to any third person who is not bound by the disclosure agreement, or it is is set forth in a U.S. patent or copyright (Inventor's right will be governed by U.S. Federal Patent and Copyright law.)

7. Except as provided by federal patent and copyright law, MRPC may use items in the public domain without obligation to the inventor.

\section{SPECIAL TERMS AND CONDITIONS}

1. Disclosures are being fumished to the MRPC by the inventor for the purpose of the evaluations, and the MRPC is not committed to further research and development which shall be the subject of a separate proposal with the inventor.

2. Prototypes received and/or recorded disclosures will be retumed to the Inventor at the concliusion of the evaluation. The non-disclosure forms completed by the Inventor shall be kept on file at the MRPC and copy forwarded to the inventor (at the inventor's cost). 
3. The MRPC is not responsible for any further actlons, decisions, or commitments made by the inventor based on the results of the MRPC evaluation.

4. Patent protection is the Imventor's responsibility.

5. The only exceptions to the non-disclosure agreement are those required by law.

The Purpose of this Non-Disclosure Agreement

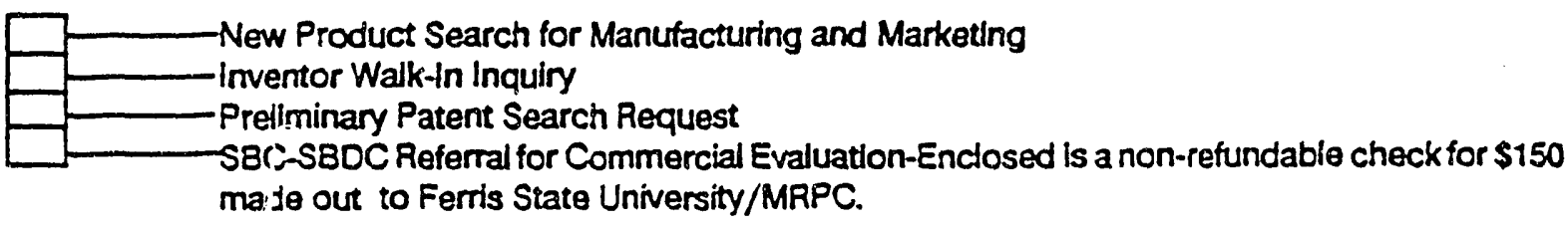

Special Instructions and Questlons

1. Is there a patent on this invention?

Is it patentable?

Yes

2. Has a full disclosure been made to the Patent Office?

If no, we urge you to make a disclosure to the Patent Office.

3. If you have a patent on this imvention, please mail a copy.

4. If there are drawings, photos, etc., please mail them also. Make sure your name and "CONFIDEN TIAL" is on every piece of material you send to us.

The name of my idea is:

Name: Date:

Address:

City/State/Zip:

MRPC Evaluator.

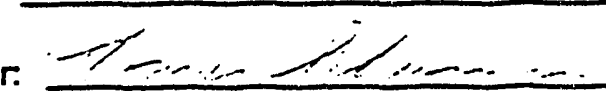
Phone:

Date: $=h-1 \%$.

Each of the undersigned agrees with the MAPC for the express benefit of the above named Inventor to abide by and be bound by the provisions of the foregoing agreement to the same extent as the MRPC is bound.

Date

Printed Name
Signature

$11 / 22 / 88$ 


\section{Ferris State University}

Manufacturing Resource and Productivity Center

Technical Assessment Questionnaire

Please complete the answers to the following questions in as much detail as possible. Attacn acditional sheots as nocessary.

Ciearty mark confidental materials as such. Do not send prototypes unless it has been requesterd.

1. General Description. Write a clear and complete description of your idea or invention. What problem does it solve? What need does it satisfy? Wito will buy the product? Why? 


\section{Stage of Development}

For the following questions please check the items which most accuracely deseribes the stage of developmeat of your idea or inveation. Check all of the icems that apply.

2. What is the patent status of this iden?
Paceac issued \#
Pateat applied for, Date: Dace:
Pacear Search Compiered
No patert steps taken to date
Idea is noc paceacable

3. What is the development status of this idea or invention?

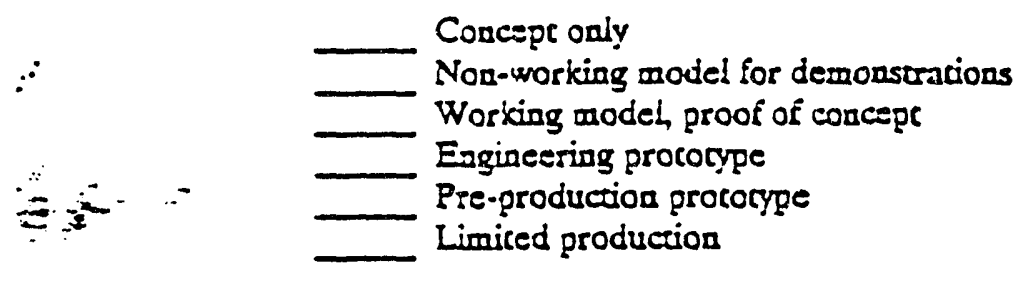

4. What product testing bas been accomplished on this invention?

\begin{tabular}{|c|c|}
\hline No cesting complesed & \\
\hline Funccional/ feasibiliry testing & by seif \\
\hline $\begin{array}{l}\text { Product safery tescing } \\
\text { Consume-/user tescing }\end{array}$ & by seif \\
\hline
\end{tabular}

5. What related research has been accomplished?

No research complered

— Tecinology and liceranure snudy

Compericive produces srudied

Marxecing researcin scudy

Pateas searcin compieted

— Commercial eraiuacion compiered

6. Classiry this invention relarive to the state of the art in this field or industry. Adapracion of exisicing produces Minor improvezenc on exisicing rechnology

Eyoiucionary/incremental improvemens on exiscing tecinoiogy

Revolutionary/radical improvemens on exiscing tecbrology

_ New recionologicad appiicarion/leap frog tecinology

7. Please provide any additional information that wiil help assess this invention's stage of development. 


\section{Mechanical Environment}

1. Please provide a drawring of the proposed product or inveacion. Ideatify and label all parts. This drawing does aot aeed to be to seale, but give a rough escimation of dimensions. If exiscing drawiags or phocographs are available please attach. Do aot send any original copies or one of a kind irems.

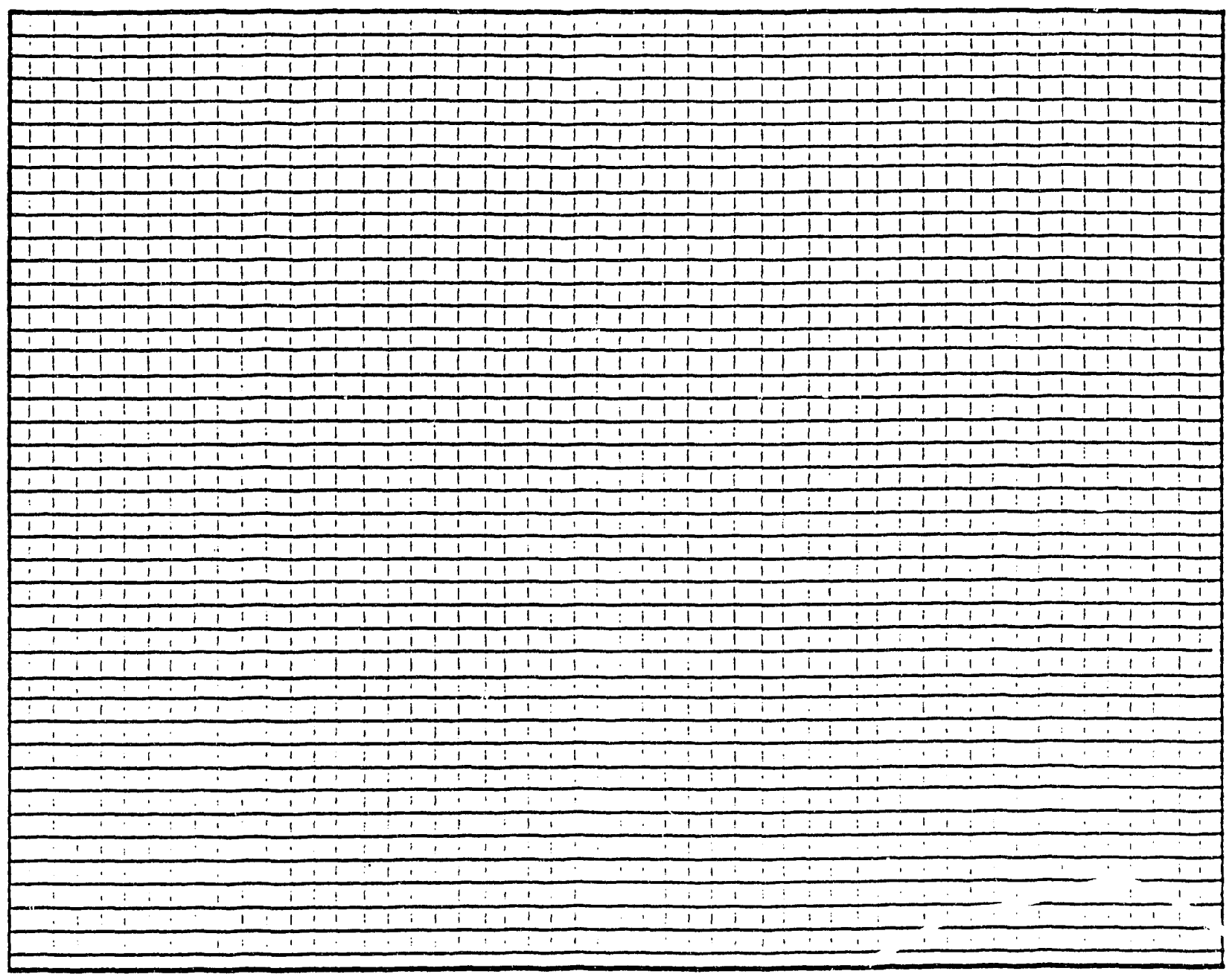

2.Please descrioe the product components (as labeled in drawing) and their operation. 
3. Describe the physical environment in which this product must operate.

4. What are the performance specifications for this product? (i.e. what needs to be accomplished for the product to be successfull).

5. What are the inputs and outputs of the product's operating system?

6. What materials are used in the manufacture of this product? Whar manuiacsuring tolerances are required in production? 


\section{Market Environment}

1. What is the targeted manufacturing cost and expected sales price for this product?

2. What production volumes are projected?

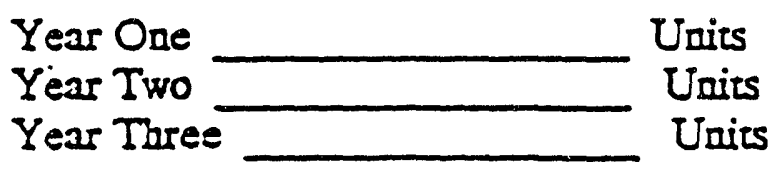

What is the basis for this projection?

3. What competitive products or processes does this invencion compere with or replace?

4. What packaging, shipoing, assembly, or distribution requirements are associated with the sales of this product? 


\section{Legal Environment}

1. What industry standards or governmeat regulations apply to the manufacture or use of this product?

2. What product liability concerns are associated with th $j$ of this product?

3. What are the environmegtal impacts from the manufacrure, use, or dispos:l of this produce? 


\section{Development Plan}

1. What best describes your curreat development plan for this idea?

In-bouse developmeac, followed by start-up of a aew business to manufacoure and market this product.

Concracted development assisennce, followed by start-up of a new business

to manufacture and markes this produce.

License produce to anocher firm for :

manufacruring and mariketing

Sell pacent oucright to anocher firm

manufacruring oxily, I will market produce.
markecing oniy, I will manufacrure produce.

Other, describe:

2. Please provide an estimated time schedule for the development, testing, manufacture, and introduccion of this product.

Acrivity

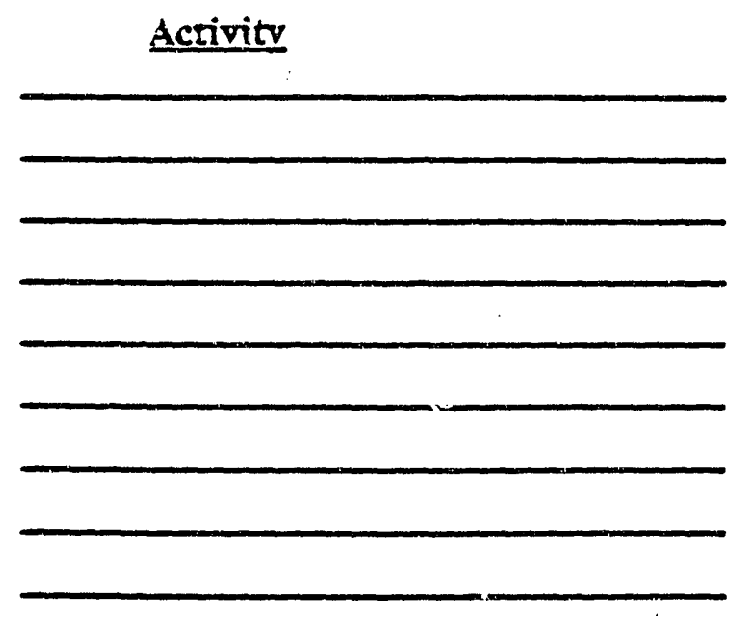

Start Date

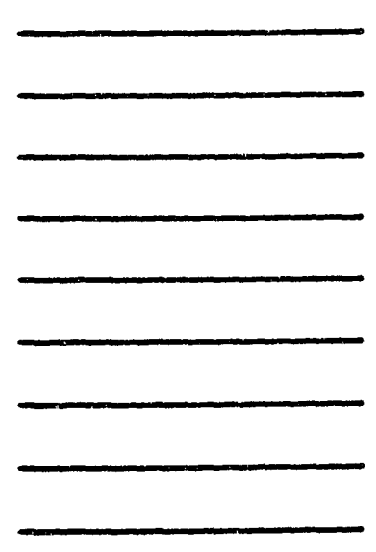

End Date

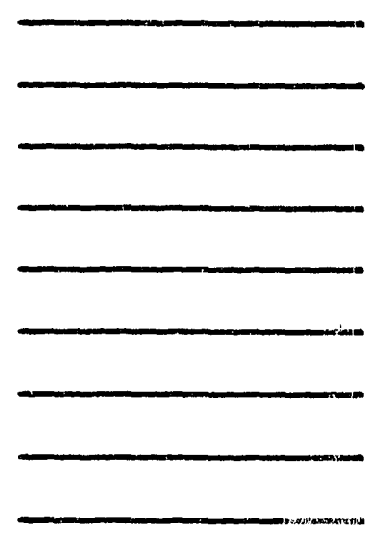

3. Please provide your estimate of the financial resources required to complete the develooment of this product. What percentnge of the funds will come from ourside funding sources? (i.e. investors, lenders) 


\section{Other Questions}

1. What problems do you foresee in the development of this product that may require out side technical assistance?

2. What specific questions would vou like to see answered in the Technical Assessment Reporr?

3. Please tell us a little about yourseif: educarion? work experience? other inventions? 
DATE FILMED $21 / 0193$ 


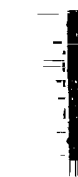

